(19). - S. 58-70. (In Rus).]

10.Паштова Л.Г. Формирование многоуровневой инвестиционной политики как фактор обеспечения экономической безопасности: дисс. ... докт. экон. наук / Л. Г. Паштова. - М.: РГБ, 2001. - 351 c. [Pashtova LG Formirovanie mnogourovnevoj investicionnoj po-litiki kak faktor obespechenija jekonomicheskoj bezopasnosti: diss. ... dokt. jekon. nauk / LG Pashtova. - M.: RGB, 2001. 351 s. (In Rus).]

11.Портрет начинающего инвестора: какие продукты выбирают, на что обращают внимание [Электронный ресурс] // Специализированный Интернет-портал banki.ru. - URL: https://www.banki.ru/news/lenta/?id=10938240 (дата обращения: 12.07.2021).

12. Салимов Л.Н. Сущность инвестиционной активности и ее значение в управлении региональной экономикой / Л.Н. Салимов // Вестник Челябинского государственного университета. - 2009. - № 9 (147). - С. 83-88 [Salimov LN Sushhnost' investicionnoj aktivnosti i ee znachenie v upravlenii regional'noj jekonomikoj / LN Salimov // Vestnik Cheljabinskogo gosudarstvennogo universiteta. - 2009. - № 9 (147). - S. 83-88. (In Rus).]

13. Соколов

Д.В.

Активизация инвестиционной деятельности инструментами региональной экономической политики: дисс. ... канд. экон. наук / Д. В. Соколов. - М.: РГБ, 2003. 223 c. [Sokolov DV Aktivizacija investicionnoj dejatel'nosti in-strumentami regional'noj jekonomicheskoj politiki: diss. ... kand. jekon. nauk / DV Sokolov. - M.: RGB, 2003. - 223 c. (In Rus).]

14.Тинькофф Инвестиции составили «Портрет современного розничного инвестора» [Электронный ресурс] // АO «Тинькофф Банк». Официальный сайт. - URL: https://www.tinkoff.ru/invest/news/342033/ (дата обращения: 12.07.2021).

15.Частные инвесторы наращивают вложения в иностранные акции, страхуясь от падения рубля [Электронный ресурс] // НАУФОР. Официальный сайт. - URL: http://www.naufor.ru/tree.asp?n=19974 (дата обращения: 12.07.2021).

УДК 332.132

ЭКОНОМИКА ТАТАРСТАНА В $2000-2020$ ГГ

DOI: 10.31618/ESU.2413-9335.2021.1.88.1418

Судьин Андрей Владимирович

кандидат эконом. наук, старший научный сотрудник, Институт востоковедения РАН, г. Москва.

\title{
ECONOMY OF TATARSTAN IN THE 2000 - 2020
}

\author{
Andrey V. Sudyin \\ PhD (Economics), senior researcher, \\ Institute of Oriental Studies of the RAS, Moscow
} \begin{abstract}
правительства республики.
Республика Татарстан входит в число наиболее развитых с точки зрения экономики регионов Российской Федерации. Политика «мягкого вхождения в рынок», проводившаяся в начале постсоветского периода, позволила Татарстану избежать многих негативных последствий радикальных экономических реформ. В последующем экономика республики вполне органично вписалась в общероссийскую экономическую модель. И при этом республика в целом за период с 2000 по 2020 гг. показывала относительно высокие темпы экономического роста.
\end{abstract}

АННОТАЦИЯ

В статье анализируется экономическая ситуация в Татарстане в период с 2000 по 2020 гг. Показана динамика объема производства в основных отраслях экономики, таких как нефтедобыча, нефтехимия, энергетика, машиностроение, сельское хозяйство. Рассматривается экономическая политика

The article analyzes the economic situation in Tatarstan in the period from 2000 to 2000 . The dynamics of production in the main sectors of the economy, such as oil production, petrochemicals, energy, mechanical engineering, and agriculture, are shown. The economic policy of the Government of the republic is considered.

Ключевые слова: Татарстан, экономика, основные отрасли, экономическая политика.

Keywords: Tatarstan, economy, main industries, economic policy.

Валовой региональный продукт Татарстана в пересчете на душу населения в 2005 году равнялся 128227 руб., а в 2015 году — 483509 руб. При этом он составлял в 2005 году $102,0 \%$ от всероссийского уровня и $140,0 \%$ от среднего уровня по регионам, входящим в Приволжский федеральный округ. В 2015 году он составил $107,7 \%$ от уровня РФ и $142,6 \%$ от уровня Приволжского федерального округа [1]. По ВРП на душу населения Татарстан в 2015 году занимал 15-е место среди 85 субъектов Российской Федерации и первое место среди 14 регионов ПФО.

В абсолютном значении валовой региональный продукт Татарстана с 2000 по 2016 гг. вырос (в 
текущих ценах) в 10,4 раза [2]. И этот рост произошел несмотря на кризис 2008 - 2009 гг. и весьма непростую экономическую ситуацию, сложившуюся в $2014-2015$ гг.

ТАБЛИЦА 2.

Валовой региональный продукт Республики Татарстан (в текущих ценах)

\begin{tabular}{|c|c|c|c|}
\hline год & ВРП (млрд руб.) & год & ВРП (млрд руб.) \\
\hline 2000 & 186,2 & 2009 & 885,1 \\
\hline 2001 & 213,7 & 2010 & 1001,6 \\
\hline 2002 & 250,6 & 2011 & 1305,9 \\
\hline 2003 & 305,1 & 2012 & 1437,0 \\
\hline 2004 & 391,1 & 2013 & 1551,5 \\
\hline 2005 & 482,8 & 2014 & 1661,4 \\
\hline 2006 & 605,9 & 2015 & 1867,3 \\
\hline 2007 & 757,4 & 2016 & 1937,6 \\
\hline 2008 & 926,1 & 2017 & 2115,5 (оценка) \\
\hline
\end{tabular}

Источники: Федеральная служба государственной статистики / Официальная статистика / Национальные счета / Валовой региональный продукт / В текущих основных ценах — всего (1998 - 2016 гг.) URL: www.gks.ru/wps/wcm/connect/rosstat_main/rosstat/ru/ statistics/accounts;

Министерство экономического развития Республики Татарстан / Основные показатели социальноэкономического развития Республики Татарстан в 2017 году. URL: http://mert.tatarstan.ru/rus/file/pub/pub_1293899.pdf.

В постоянных ценах темпы роста ВРП в период с 2000 по 2008 гг. составляли от $3,6 \%$ до $11,0 \%$ в год. В 2009 году, в результате кризиса, ВРП республики сократился на $3,4 \%$. Однако в дальнейшем он снова демонстрировал положительную динамику, хотя темпы его роста снизились, по сравнению с докризисным периодом: в 2010 году они составили 4,3\%; в 2011 - 5,7\%; в $2013-2,4 \%$; в $2014-2,1 \%$. В 2015 году ВРП Татарстана остался на уровне предшествующего года, а в 2016 году вновь увеличился (правда, лишь на 1\%) [3]. 2017 году ВРП Татарстана вырос на 2,8\% [4]. Несмотря уменьшение темпов роста ВРП, Татарстан по динамике данного показателя в период с 2011 по 2017 гг. превосходил как Приволжский федеральный округ, так и Российскую Федерацию в целом. По общему объему ВРП он в 2016 году, по данным Росстата, занимал восьмое место в России (после Москвы, Санкт-Петербурга, Московской области, Ханты-Мансийского округа, Краснодарского края, Свердловской области и Ямало-Ненецкого округа). В 2017, по данным Министерства экономического развития Татарстана, республика заняла: по объему ВРП шестое место среди регионов Российской Федерации; по промышленному производству и строительству — пятое место; по сельскому хозяйству — третье место; по вводу жилья восьмое место; по обороту розничной торговли восьмое место; по объему инвестиций в основной капитал - четвертое место [4].

Важнейшей отраслью экономики Татарстана является добыча полезных ископаемых и, прежде всего, нефти. С 1943 года по настоящее время в республике добыто около 4 млрд тонн нефти (2007 году была утверждена специальная медаль «В ознаменование добычи трехмиллиардной тонны нефти Татарстана»). В 2000 году объем нефтедобычи в Татарстане составил 27,2 млн тонн, в
$2005-30,7$ млн, в $2010-32,5$ млн тонн [5]. В 2017 году в республике было добыто 35,8 млн тонн нефти, что составило 6,5\% всей нефти, добытой в Российской Федерации [6]. Доля «Татнефти» в общем объеме нефтедобычи в Татарстане в 2000 году равнялась 84,9\%, в 2005 году $-82,4 \%$, в 2010 году - 79,7\% и в 2017 году — 79,8\%. Доля малых нефтяных компаний в эти годы составила, соответственно, 15,1\%, 17,6\%, $20,3 \%$ и 20,2\%. В 2017 году в Татарстане действовали 32 малые компании, занимающиеся добычей нефти [7]. С 1997 года, когда был издан указ Минтимера Шаймиева «О мерах по увеличению нефтедобычи в РТ», давший старт созданию малых нефтяных компаний, ими было добыто примерно 100 млн тонн нефти [8].

В целом добыча полезных ископаемых обеспечила в 2005 году $30,9 \%$ валового регионального продукта Татарстана, в 2012 году $23,4 \%$ [9]. В 2017 году ее доля в ВРП составила $21,5 \%$ [10].

При этом экономику Татарстана нельзя назвать однобокой. Так, на долю обрабатывающих производств в 2005 году приходилось 16,9\% валового регионального продукта, в 2012 году $18,3 \%$, а в 2017 году - 18,5\%. Доля строительства в 2005, 2012 и 2017 гг. достигала 10,0\%, 10,1\% и $7,7 \%$ ВРП. Доля сельского хозяйства в эти годы составила, соответственно, 7,8\%, 5,6\% и 7,4\%. На долю оптовой и розничной торговли приходилось $11,2 \%, 14,9 \%$ и $14,1 \%$. На долю транспорта и связи - 7,3\%, 8,4\% и 8,1\%. Соответственно $15,9 \%$, $19,3 \%$ и 22,7\% ВРП пришлось на долю всех прочих сфер экономики [11].

В структуре промышленности доля добычи полезных ископаемых в 2010 году составила $28,7 \%$, а в 2017 году - 24,0\%. Доля обрабатывающих производств в общей структуре промышленности в эти годы составила $62,8 \%$ и $69,2 \%$ (в том числе: доля 
нефтеперерабатывающей, химической и нефтехимической промышленности - 29,6\% в 2010 году и $33,9 \%$ в 2017 году; доля машиностроения - соответственно 22,9\% и $23,2 \%$ [12]. Суммарный объем отгруженной промышленной продукции (по всем отраслям промышленности) в Татарстане с 2011 по 2017 гг. увеличился с 1345,3 млрд руб. до 2254,2 млрд руб. [12]. Причем темпы его роста в республике были выше, чем в целом по Российской Федерации.

Этот рост в значительной степени явился результатом развития обрабатывающих производств, в том числе нефтепереработки и нефтехимии. В 2011 году в Нижнекамске был введен в эксплуатацию крупный нефтеперерабатывающий и нефтехимический комплекс «ТАНЕКО», контролируемый компанией «Татнефть». Там же в Нижнекамске был запущен в эксплуатацию и второй комплекс - «ТАИФ-НК» (в составе частной региональной группы компаний «ТАИФ»).

Из 35,7 млн тонн нефти, добытой в Татарстане в 2017 году, 16,3 млн тонн (то есть $45 \%$ ) были отправлены на переработку. Нефтеперерабатывающие предприятия Татарстана в 2017 году произвели отгруженной продукции на 386,5 млрд руб. На долю данной отрасли пришлись $17,1 \%$ общего объема промышленного производства в республике. В 2017 в Татарстане было произведено 3141,4 тыс. тонн прямогонного бензина, 561,6 тыс. тонн автомобильного бензина, 3741,9 тыс. тонн дизельного топлива и 2109,5 тыс. тонн мазута [13].

Заметную место в структуре экономики Татарстана занимают также химия и нефтехимия. Суммарный объем отгруженной продукции данных отраслей в 2017 году составил 285,4 млрд руб., что составило $12,7 \%$ всего промышленного производства в республике. При этом на долю Татарстана пришлось примерно $12 \%$ химической и нефтехимической продукции, произведенной в Российской Федерации. Крупнейшими предприятиями данного профиля в республике являются «Нижнекамскнефтехим», «Казаньоргсинтез», «УК Татнефть-Нефтехим» и «Нэфис-Косметикс». В 2017 году в республике было произведено 1668,4 тыс. тонн пластиков, 936,9 тыс. тонн полиэтилена, 712,7 тыс. тонн синтетических каучуков, 212,0 тыс. тонн полипропилена, 134,3 тыс. тонн технического углерода и 439,8 тыс. тонн удобрений [14]. Было также произведено 14 млн автомобильных шин [15].

Как было показано выше, третью позицию в структуре промышленного производства в Татарстане (после добычи полезных ископаемых и производств, относящихся к нефтепереработке, нефтехимии и химии) занимает машиностроение, включая автомобилестроение. Причем в 2017 году по своей доле в промышленном производстве машиностроительная группа отраслей вплотную приблизилась к нефтедобыче. Флагманом машиностроения в республике является автозавод КамАЗ в Набережных Челнах. Кроме него, сборка автомобилей ведется на совместном российскоамериканском предприятии «Форд-Соллерс». Всего в 2017 году в Татарстане было произведено 53,2 тыс. грузовых и 24,0 тыс. легковых автомобилей. Вклад автомобильной промышленности в общий объем промышленного производства в Татарстане в 2017 году составил 11,7\%. На долю КамАЗа к 2020 году приходилось $45 \%$ российского рынка тяжелых грузовиков. Концерн входит в число 20 крупнейших мировых производителей данного класса автомобилей [16].

Наряду с автомобилестроением, в республике также имеются авиастроительные и судостроительные предприятия. Среди них можно выделить Казанский авиационный завод имени С.П.Горбунова (филиал ПАО «Туполев») и Казанский вертолетный завод (входящий в холдинг «Вертолеты России»), а также Зеленодольский судостроительный завод имени А.М.Горького.

Важную роль в экономике Татарстана играет сельское хозяйство. В 2005 году объем продукции данной отрасли в республике составил 68,1 млрд руб., в 2011 году — 150,4 млрд, в 2017 году — 256,1 млрд руб. [17]. На долю Татарстана к началу 2020 -х годов приходилось $2,3 \%$ российских сельскохозяйственных угодий. При этом республика производила 4,5\% валовой продукции сельского хозяйства в России. В 2017 году республика занимала третье место среди регионов Российской Федерации по общему объему сельхозпродукции, первое место по производству товарного молока (1821,6 тыс. тонн), шестое место по производству мяса, включая мясо птицы (491,6 тыс. тонн) и восьмое место по сбору зерна (4868,2 тыс. тонн). Также в 2017 году в Татарстане было произведено 1,4 млн тонн картофеля, 3,1 млн тонн сахарной свеклы, 0,4 млн тонн овощей и 1,2 млрд штук куриных яиц [18]. По состоянию на 2017 год в республике насчитывалось свыше 30 крупных агрохолдингов, 451,2 тыс. личных подсобных хозяйств и 4,6 тыс. фермерских хозяйств [18].

Доля строительства в валовом региональном продукте Татарстана в 2012 - 2017 гг. несколько сократилась (как было показано выше). Однако в абсолютном выражении объем строительства вырос. В 2012 году в республике было сдано в эксплуатацию 2399,5 тыс. кв. м жилья, а в 2017 году — 2408,1 тыс. кв. м (в том числе 535,5 тыс. кв. м - по программе социальной ипотеки) [19].

Экономический рост в Татарстане в «нулевые» и 2010 годы сопровождался ростом доходов жителей республики. Среднедушевые денежные доходы населения Татарстана составили в 2005 году 7383 руб., в 2010 году 18424 руб. и в 2016 году - 32609 руб. По данному показателю республика в 2016 году занимала 16 место среди 85 регионов России. При этом среднедушевые доходы в Татарстане составили $106,0 \%$ от общероссийского уровня и $126,7 \%$ от уровня Приволжского федерального округа [20, С. 242-243]. Среднемесячная номинальная зарплата работников организаций в республике в 2005 году составила 7068 руб., в 2010 году - 17350 руб. и в 
2016 году - 30224 руб. Этот показатель в Татарстане в 2016 году был на 17,7\% ниже общероссийского уровня, но на $10,9 \%$ превосходил уровень ПФО [20, С. 244-245]. В апреле 2018 года средняя заработная плата в республике достигла 34863 руб. [21]. В течение всего периода «нулевых» и 2010-х годов Татарстан как по размеру среднедушевого дохода, так и по среднемесячной заработной плате делил с Пермским краем 1-2 места в Приволжском федеральном округе, значительно опережая остальные 12 регионов ПФО.

Доходы населения являются важным, но не единственным фактором, влияющим на качество жизни. По совокупности этих факторов в рамках Программы развития ООН ежегодно составляется Национальный доклад с индексами развитии человеческого потенциала (ИРЧП) в Российской Федерации. В Докладе рассматриваются приоритетные для человека вопросы: рост благосостояния и уровня занятости, борьба с бедностью, повышение образовательного уровня, улучшение здоровья и решение демографических проблем, совершенствование институциональных условий развития экономики, экологическая и энергетическая безопасность, обеспечение равенства, проблемы, связанные с изменением климата. Также представлен анализ российских региональных проблем человеческого развития, обобщен положительный опыт российских регионов. В этом ежегодном докладе Татарстан постоянно занимает одно из ведущих мест. Так, по приведенному в докладе за 2014 год индексу развития человеческого потенциала, Татарстан в 2011 году занимал четвертое пятое место в Российской Федерации, уступая лишь Москве, Санкт-Петербургу и Тюменской области (включая входящие в область Ханты-Мансийский и ЯмалоНенецкий округа). В Татарстане ИРЧП составил 0,880 , а в целом по России - 0,854 пункта [22]. В качестве базы для определения данного индекса использовались: индекс доходов, индекс долголетия и индекс образованности. Причем Татарстан показал один из лучших показателей сбалансированности данных индексов. В докладе говорилось: «Помимо федеральных городов, только Белгородская область, Республика Татарстан и, в меньшей степени, Томская область имеют высокий рейтинг по всем трем индикаторам ИРЧП, развитие человеческого потенциала в них более сбалансировано».

Кроме индекса ИРЧП, Татарстан и по целому ряду других индексов развития входит в число передовых регионов России. Это подтверждается различными рейтинговыми исследованиями, проводившимися после 2000 года. Так, по параметрам конкурентоспособности регионов, рассчитанным по методике Давосского экономического форума, Республика Татарстан в 2008 году заняла одно из ведущих мест в России, эквивалентное $45-50$ месту в мировом рейтинге (что соответствует, например, уровню Кипра) [23]. А согласно докладу «Измерение условий ведения бизнеса в российских регионах», который был подготовлен Российской экономической школой совместно с аудиторской компанией «Ernst and Young», Татарстан был признан наиболее привлекательным регионом для ведения бизнеса в Российской Федерации [24]. В 2011 году Татарстан занял первое место в рейтинге лучших российских регионов по условиям для предпринимательской деятельности, составленном американским журналом «Forbes» [25]. Согласно Национальному рейтингу состояния инвестиционного климата в субъектах Российской Федерации, составляемому Агентством стратегических инициатив, Татарстан в 2015 - 2017 гг. занимал первое место среди регионов России. В 2018 году он пропустил вперед Тюменскую область и Москву, но остался в тройке лидеров [26].

Высокие инвестиционные рейтинги Татарстана, свидетельствуют об эффективности работы республиканских властей по созданию благоприятной среды для ведения бизнеса. И они, несомненно, способствуют привлечению в республику инвестиций (как из российских, в том числе местных, источников, так и из-за рубежа). В 2012 году инвестиции в основной капитал в Татарстане составили 479,8 млрд руб., в 2014 году — 542,8 млрд, в 2016 году — 636,5 млрд [27]. По данному показателю республика занимает первое место в Приволжском федеральном округе, значительно опережая все остальные регионы. Структура инвестиций в основной капитал по видам экономической деятельности в 2016 году была следующей: сельское хозяйство (включая охоту и лесное хозяйство) - 4,6\%; добыча полезных ископаемых - 12,7\%; обрабатывающие производства - 35,7\% (в том числе: производство нефтепродуктов - 20,3\%; химическое производство - 4,8\%; производство транспортных средств и оборудования - 3,3\%; производство пищевых продуктов, напитков и табака - 2,1\%); производство и распределение электроэнергии, газа и воды - 7,2\%; транспорт и связь - 12,0\%; операции с недвижимым имуществом, аренда и предоставление услуг - 16,0\%; остальные виды деятельности - 11,8\% [28].

А в октябре и ноябре 2017 года Всероссийский центр изучения общественного мнения (ВЦИОМ) провел развернутый социологический опрос населения Татарстана, в котором приняли участие свыше 1500 респондентов. Согласно его результатам, 77\% всех опрошенных отметили, что довольны общей ситуацией в республике (в целом по Российской Федерации этот показатель составил 64\%.). А недовольны положением дел в Татарстане были только 18\%. При этом половина респондентов высказали мнение, что в Татарстане в целом живется лучше, чем в других регионах России. О том, что в республике живется хуже, заявили лишь $12 \%$ [29]. Таким образом, опрос показал, что жители Татарстана не только высоко оценивают положение в республике, но и в значительной 
своей части считают, что общая ситуация в Татарстане (по многим показателям) лучше, чем в целом ряде других регионов Российской Федерации. Конечно, это мнение носит субъективный характер, но оно вполне соответствует приведенным выше данным об индексе развития человеческого потенциала, который в Татарстане в 2010-х годах был заметно выше, чем в остальных регионах Приволжского федерального округа, и превосходил среднероссийский уровень.

\section{Список использованной литературы}

1. Федеральная служба государственной статистики Российской Федерации / Официальная статистика / Национальные счета / Валовой региональный продукт / В текущих основных ценах на душу населения (1998-2016 гг.) URL: www.gks.ru/wps/wcm/connect/rosstat _main/rosstat/ru/statistics/accounts/.

2. Федеральная служба государственной статистики Российской Федерации / Официальная статистика / Национальные счета / Валовой региональный продукт / В текущих основных ценах - всего (1998-2016 гг.) URL: www.gks.ru/wps/wcm/connect/rosstat_main/rosstat/ru /statistics/accounts/.

3. Федеральная служба государственной статистики Российской Федерации / Официальная статистика / Национальные счета / Валовой региональный продукт / Индексы физического объема в процентах к предыдущему году (19982016гг.) URL: www.gks.ru/wps/wcm/connect/rosstat _main/rosstat/ru/statistics/accounts/.

4. Министерство экономического развития Республики Татарстан / Основные показатели социально-экономического развития Республики $\begin{array}{lllll}\text { Татарстан в } & \text { в } 2017\end{array}$ http://mert.tatarstan.ru/rus/file/pub/pub_1293899.pdf.

5. Борисов Д., Мустафин А. Перспективы дальнейшего развития нефтегазового сектора Республики Татарстан: возможности и риски // Нефтегазовая вертикаль (электронная версия). M., 12.08.2013. URL: http://www.ngv.ru/pr/perspektivy-dalneyshegorazvitiya-neftegazovogo-sektora-respubliki-tatarstanvozmozhnosti-i-riski-/?sphrase_id $=687483$.

6. Татарстан в 2017 году сохранил объем добычи нефти на уровне 2016 года // Электронная газета «ТACC». - M., 26.01.2018. URL: https://tass.ru/ekonomika/4906682.

7. Информационно-новостной сайт «KazanFirst». https://kazanfirst.ru/articles/472661.

8. Бизнес-Online. Деловая электронная газета Татарстана, 12.07.2017. URL: https://www.businessgazeta.ru/article/351239.

9. Социально-экономическое развитие Республики Татарстан в 2012 году. - Казань, Министерство экономики РТ, 2013, с. 7; Федеральная служба государственной статистики Российской Федерации / Официальная статистика / Национальные счета / Валовой региональный продукт / Структура ВРП по отраслям экономики. URL: http://www.gks.ru/free_doc/new_site/vvp/tabvrp2.htm.

10. Министерство экономического развития Республики Татарстан / Основные показатели социально-экономического развития Республики Татарстан в 2017 г. URL: http://mert.tatarstan.ru/rus/file/pub/pub_1293899.pdf.

11. Федеральная служба государственной статистики Российской Федерации / Официальная статистика / Национальные счета / Валовой региональный продукт / Структура ВРП по отраслям экономики. URL: http://www.gks.ru/free_doc/new_site/vvp/tab-

vrp2.htm; Социально-экономическое развитие Республики Татарстан в 2012 году. - Казань, Министерство экономики РТ, 2013, с. 7; Министерство экономического развития Республики Татарстан / Основные показатели социально-экономического развития Республики Татарстан в 2017 году. URL: http://mert.tatarstan.ru/rus/file/pub/pub_1293899.pdf.

12. Министерство экономического развития Республики Татарстан / Основные показатели социально-экономического развития Республики Татарстан в 2017 г. URL: http://mert.tatarstan.ru/rus/file/pub/pub_1293899.pdf.

13. Информационный портал «Made in Tatarstan» / Нефтепереработка. URL: http://madeintatarstan.com/promo-refining.

14. Информационный портал «Made in Tatarstan» / Химическая промышленность. URL: http://madeintatarstan.com/promo-chemistry.

15. Информационно-новостной сайт «KazanFirst».

URL: https://kazanfirst.ru/articles/472661.

16. Информационный портал «Made in Tatarstan» / Автомобильная промышленность. URL: http://madeintatarstan.com/promo-auto.

17. Эксперт Татарстан. - Казань, 05.11.2015. URL: https://expertrt.ru/tema/1120-urozhajsubsidij.html; Министерство экономического развития Республики Татарстан / Основные показатели социально-экономического развития Республики Татарстан в 2017 г. URL: http://mert.tatarstan.ru/rus/file/pub/pub_1293899.pdf.

18. Информационный портал «Made in Tatarstan» / Сельское хозяйство. URL: http://madeintatarstan.com/promo-farm.

19. Министерство экономического развития Республики Татарстан / Основные показатели социально-экономического развития Республики Татарстан в 2017 г. URL: http://mert.tatarstan.ru/rus/file/pub/pub_1293899.pdf.

20. Регионы России. Социальноэкономические показатели. 2017. - М.: Федеральная служба государственной статистики (Росстат), 2017.

21. Средняя зарплата в России по регионам в 2018 году // портал «Финансовая возможность» (fincan.ru). URL: http://fincan.ru/articles/16 _srednyaya-zarplata-v-rossii-po-regionam-v-2018godu. 
22. Зубаревич Н.В. Развитие и человеческий потенциал регионов // Доклад о человеческом развитии в Российской Федерации за 2014 год / под ред. Л.М.Григорьева и С.Н.Бобылева. - М.: Аналитический центр при Правительстве Российской Федерации, 2014. С. 40.

23. Итоги. - М., 27.10.2008.

24. Социально-экономическое развитие Татарстана: тенденции, перспективы, возможности // Деловой центр Республики Татарстан. Интернетпортал 《TatCenter.ru». URL: http://info.tatcenter.ru/online/35.

25. Лучшие регионы для бизнеса // Forbes (русское издание - электронный вариант), 30.05.2011.

26. Макаркина Н. Национальный рейтинг инвестклимата в 2018 году возглавила Тюменская область // Новости Агентства стратегических инициатив, 25.05.2018. URL: https://asi.ru/news/91678/

УДК 33

ГРНТИ 63.03
27. Территориальный орган Федеральной службы государственной статистики по Республике Татарстан / Официальная статистика / Предпринимательство / Инвестиции / Основные показатели инвестиционной деятельности в Республике Татарстан. URL: http://tatstat.gks.ru/ wps/wcm/connect/rosstat_ts/tatstat/ru/statistics/enter prises/investment/

28. Территориальный орган Федеральной службы государственной статистики по Республике Татарстан / Официальная статистика / Предпринимательство / Инвестиции / Инвестиции в основной капитал по видам экономической деятельности. URL: http://tatstat.gks.ru/ wps/wcm/connect/rosstat_ts/tatstat/ru/statistics/enterpr ises/investment/

29. Информационно-новостной сайт «KazanFirst». 11.12.2017. URL: https://kazanfirst.ru/articles/454252.

\title{
К ВОПРОСУ РАЗВИТИЯ ЦИФРОВОЙ ЭКОНОМИКИ В ПРИВОЛЖСКОМ
} ФЕДЕРАЛЬНОМ ОКРУГЕ

Еремичева О.Ю.

к.э.н., доиент, доцент

Мащенко М.О.

студент

Панкова А.В.

студент

Самарский государственный технический университет,

(Россия, г. Самара)

\section{ON THE DEVELOPMENT OF THE DIGITAL ECONOMY IN THE VOLGA FEDERAL DISTRICT}

\author{
O.Yu. Eremicheva, \\ $P h D$ in economics \\ M. Mashchenko, \\ student \\ A. Pankova \\ student \\ Samara State Technical University, \\ (Samara, Russia)
}

\begin{abstract}
АННОТАЦИЯ
Проведен анализ понятия «цифровая экономика», выделены нормативно-правовые акты в области цифровизации. В ходе работы были установлены показатели цифровизации экономики. На основе данных показателей проведен анализ уровня цифровизации Приволжского федерального округа. Определена роль цифровизации в региональном аспекте. В процессе анализа выявлены проблемы в развитии цифровой экономики и предложены направления по их решению.

\section{ANNOTATION}

The analysis of the concept of "digital economy" is carried out, regulatory legal acts in the field of digitalization are highlighted. In the course of the work, indicators of the digitalization of the economy were established. Based on these indicators, the analysis of the level of digitalization of the Volga Federal District is carried out. The role of digitalization in the regional aspect is determined. In the course of the analysis, problems in the development of the digital economy are identified and directions for their solution are proposed.

Ключевые слова: цифровизация, цифровая экономика, показатели цифровой экономики, цифровые технологии, региональное развитие.

Keywords: digitalization, digital economy, indicators of the digital economy, digital technologies, regional development.
\end{abstract}

